\title{
LOXOSCELISMO CUTANEO
}

\author{
Dr. MARIO GUTIERREZ LEYTON
}

Hospital San Fernando. Servicio Nacional de Salud.

E1 problema de los accidentes causados por mordeduras de arañas ha estado de actualidad en el último tiempo. Incluso el Servicio Nacional de Salud se ha preccupado de difundir públicamente las modalidades del aracnoidismo con el objeto de enfatizar las recomendaciones profilácticas.

Sin embargo, no sólo el profano asiste al drama del cuadro de intoxicación por mordedura de araña cuando éste se ha producido, sino que con cierta frecuencia el médico debe atender pacientes de este tipo, con elementos terapéuticos insuficientes o con conocimientos no bien definidos. En el ambiente rural de Chile esta aseveración adquiere mayor importancia, por ser éste el escenario preferido de una de nuestras dos especies de arañas da reconocida capacidad patógena, el Latrodectus mactans o "araña de abdomen colora. do". No debemos dejar de considerar que la otra especie, el Loxosceles laeta "araña de los rincones" o "de detrás de los cuadros", de hábitos domésticos, se encuentra en el interior de las casas tanto de zonas urbanas como rurales 1.2-5-6.

La presente observación clínica corresponde precisamente a un caso de Loxoscelismo cutáneo, seguido en el Hospital de San Fernando.

J. M. P. D. Obs. 25235. Niño de 5 meses de edad, procedente de la localidad rural de Puente Negro, situada al interior de San Fernando. Ingresa al hospital a principios de Diciembre, porque dos días antes amaneció con un gran edema y abundante secreción muco-serosa del ojo derecho. En el examen se aprecia un lactante eutrófico con 7.150 gramos de peso que presenta un edema elástico que compromete los párpados y mejilla derechos. En la parte central de la mejilla se observa una placa violácea circunscrita, de alrededor de 2,5 centímetros de diámetro, indurada y muy dolorosa a la palpación. No se constatan adenopatías regionales. El edema ocluye la hendidura palpebral, de la cual fluye una abundante secreción serosa. Se aprecia además un trismus incipiente con conservación del reflejo de la deglución, aunque el dolor impide mamar al niño.

El comienzo brusco de la sintomatología y las características de la lesión cutánea hicieron que nos planteáramos el diagnóstico de Loxoscelismo cutáneo. Esta impresión fué reforzada por la información proporcionada por la madre del niño, que nos dijo que frecuentemente habia observado arañas en el interior de la casa, incluso en el dormitorio, arañas cuya descripción coincidía bastante con la que teníamos del Laxosceles laeta - de color café, de más o menos un centímetro de longitud y sin manchas apreciables.

Como tratamiento se indicó Prednisona 2,5 milígramos cada ocho horas, con una dosis total de 75 milígramos. Colirio de Cloramfenicol y Penicilina sódica 100.000 unidades, tres veces al dia, para prevenir infecciones secundarias.

Al día siguiente del ingreso el edema habia aumentado y se extendia hasta el hemicráneo derecho, manteniendo su consistencia elástica, doloroso, y agregándose un pequeño aumento de la temperatura local. La placa se presentaba más oscura, con los bordes flictenoides y habia aparecido un pequeño elemento similar en la región mastoidea derecha.

Todas estas manifestaciones se fueron atenuando en forma paulatina, al mismo tiempo que la placa se transformó en una escara negruzca que terminó por caer al cabo de 14 dias, quedando al descubierto las planos profundos al mismo tiempo que una extensa zona infectada con despegamiento de planos. (Fig. 1). Se practicó un examen de orina que resultó normal. En un hemograma se encontró 3.500 .000 eritrocitos con un $65 \%$ de hemoglobina y 17.400 leucocitos.

Se inicia aseo diario con Varidasa en forma de apósitos húmedos cada 8 horas (a la concentración por centímetro cúbico de 5.000 unidades de Estreptokinasa y 1.250 unidades de Estreptodornasa) y 

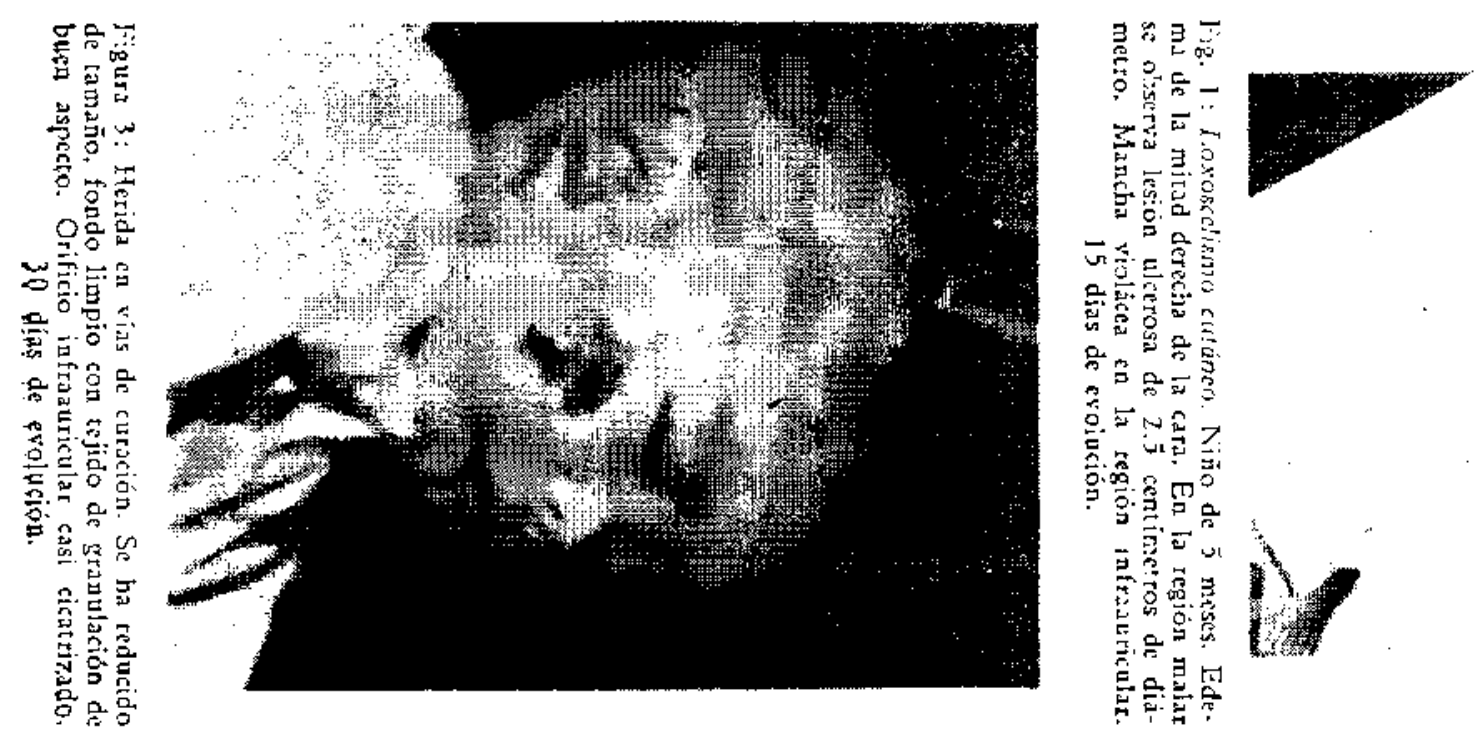

ज宓 $=\frac{0}{2}$

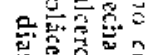

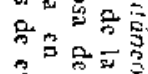

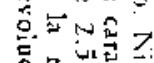

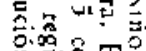

要:

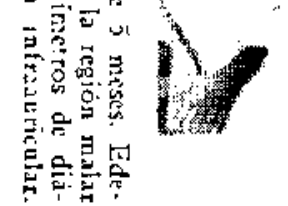

4
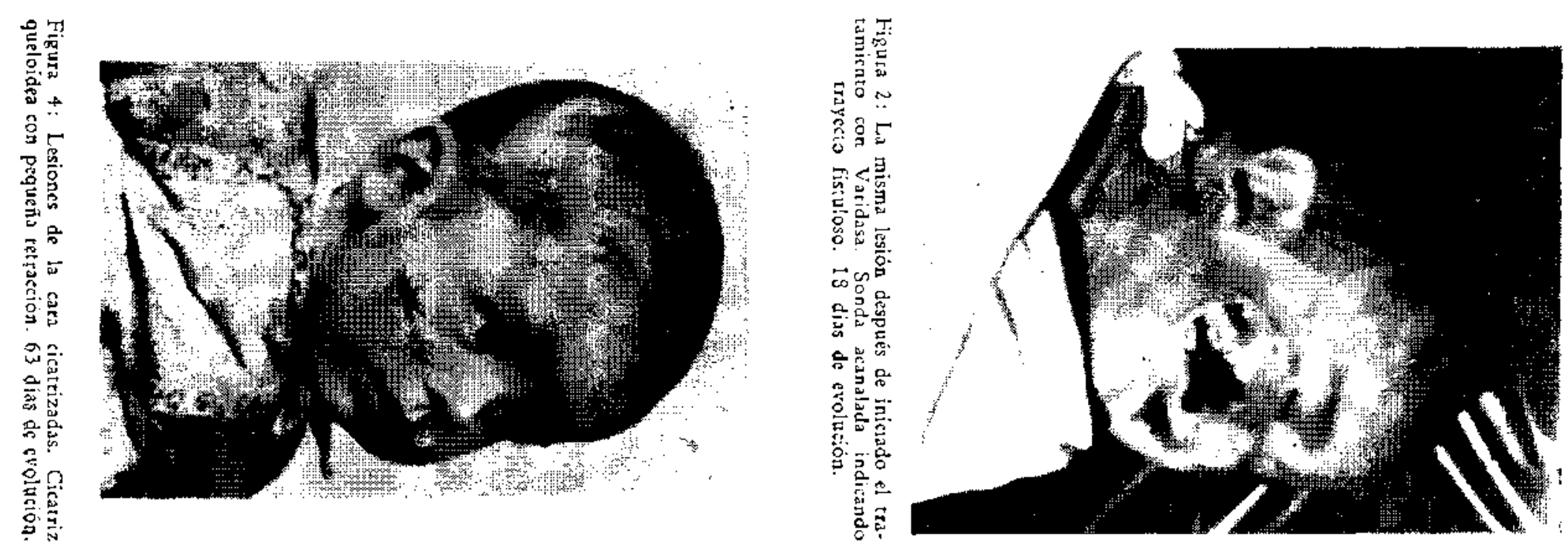
rodeando la zona con ungüento dérmico de Cloramfenicol. Al cabo de 24 horas se obtiene una limpieza impresionante que permite, mediante una sonda acanalada, ta exploración de un trayecto fistuloso ubicado entre la piel y planos profundos, que se extiende desde la zona malar a la infraauricular derecha. (Fig. 2).

EI décimo sexto día intercurre un trastorno nutritivo agudo que curó al cabo de seis días. Se prosigue el aseo diario mediante la perfusión local de Varidasa mezclada con Clorhidrato de Tetraciclina para uso intravenoso, durante dos semanas, al final de las cuales se advierte acentuada mejoría de la herida en la que se observa acercamiento de los bordes y fondo limpio con tejido de granulación de buen aspecto. La fístula infraauricular drena escaso liquido de aspecto purulento, pero tiende al cierre espontáneo. (Fig. $3)$. Se ejecuta dermatoplastía, aprovechando un colgajo de piel de la cara anterointerna del brazo derecho. Por desgracia, cuatro dias más tarde, se empieza a insinuar la pérdida paulatina del injerto, la que se completa a la semana siguiente. Reanudamos el aseo diario con Varidasa, con lo que se consigue una progresiva granulación de la herida, pero con esbozo de retracción fibrosa. Esta última circunstancia decide el alta (45 dias de evolución) y la indicación de concurrir a un centro quirúrgico de Santiago que dé mejores garantías de buen éxito a la reparación quirúrgica.

Aproximadamente un mes y medio después, sin haber cumplido la recomendación de la consulta en Santiago, concurre a control a nuestro Hospital. donde se comprueba la completa curación de las lesiones de la cara, con pequeña retracción $\mathrm{y} \sin$ compromiso funcional de los órganos vecinos. (Fig. 4).

\section{COMENTARIO}

El diagnóstico etiológico de este caso de Loxoscelismo cutáneo. a pesar de no haberse visto ni capturado la araña causante de la mordedura, nos parece evidente. Favorecen esta apreciación los siguientes hechos, que también han observado otros autores $5 \cdot 6$ : a) La iniciación repentina del cuadro, aparentemente durante el sueño nocturno. b) La procedencia del paciente, en cuyo domicilio la madre ha- bia encontrado arañas, presumiblemente del género Loxosceles, asociada a la información de haberse registrado casos de Loxoscelismo en pacientes de esa misma zona. d) Las características clínicas de la lesión cutánea, sin compromiso ganglionar, y su evolución.

A nuestro parecer la gravedad del cuadro local estuvo condicionada por la corta edad del paciente, la cantidad del veneno inoculado y la tardanza con que se inició el tratamiento, puesto que habian transcurrido más de $\mathbf{4 8}$ horas cuando el niño fué traído a consulta.

Tenemos la impresión, que a pesar de todo, la Prednisona contribuyó a localizar y dclimitar el cuadro local, y en especial redujo la inflamación de la zona perioral con lo que se pudo restablecer rápidamente la vía normal de alimentación. Nos parece que la Varidasa influyó en forma considerable en la restitución local de los tejidos.

Por último diremos que es de importancia práctica tener presente el diagnóstico de Loxoscelismo en cuadros similares al que hemos observado, aun en ausencia de la araña agresora, por cuanto al no disponer del suero anti-tóxico específico, el empleo oportuno de antihistamínicos inyectables se ha demostrado eficaz en estas formas cutáneas $5 \cdot$, en tanto que Ios corticoides suprarrenales han sido de positivo beneficio en las formas graves de Loxoscelismo cutáneo-visceral ${ }^{\text {3.7 }}$. El uso de los anti-histamínicos se iustificaría porque en estudios experimentales se ha observado que en la intoxicación por veneno de Loxosceles lacta se produce un cuadro de tipo anafilaciódeo local ${ }^{*}$.

\section{BIBLIOGRAFÍA}

1.-BERTIN, V. - Consideracionrs sibre aracnotdtsmo cn Chile. Rev. Chileñ his. $13: 37-50,1950$

2.-MACCHAVELO, A. - Aracnolrismo cutanco o mancha gangrenosa en Chile. Puerto Rito. J. Pub. Health. 27:467-503, 1947 .

3. MENEGHELIO, J. Y EMPARANZA, E. - Loxosecllsmo cuténeo-vlsceral y Cort'sond. Bol. Inf. Parasit. Chltenas. 7:11-12, 1952 .

4.-PIZZI. T.; ZACARIAS, J. y SCHENONE, H. - BStudto histopetologico expertmental en el envenenamiento por Laxosceles laet3. Blologica. 23:33-51. 1957.

5.-PRATS, F. y SCHENONE. H. - Mordeduras de a nas. Nuevas consideraclones sobra Loxoscellsmo. Bol. Chileno Parasit. 12:7-9, 1957.

6. -SCHENONE, H. - DStudio de 2 T casos de Loxoscellsmo. Bol. Chlleno Paraslt. 14:7-13, 1959.

7. SCHENONE, H.: SPMPREVIVO, L. Y SCHIRMER. E. Conslderaclones a propasito de dos casos de Loxos-

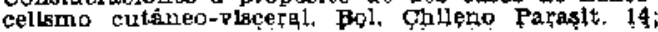
$19-31,1059$. 